\title{
Hydrogen sulfide promotes cell proliferation of oral cancer through activation of the COX2/AKT/ERK1/2 axis
}

\author{
SHUAI ZHANG ${ }^{1,2}$, HUAN BIAN ${ }^{3}$, XIAOXU LI ${ }^{2}$, HUANHUAN WU ${ }^{4}$, \\ QINGWEI BI $^{5}$, YINGBIN YAN ${ }^{6}$ and YIXIANG WANG ${ }^{1}$ \\ ${ }^{1}$ Central Laboratory, Peking University School and Hospital of Stomatology, Beijing; ${ }^{2}$ Department of Oral and \\ Maxillofacial Surgery, Peking University School and Hospital of Stomatology, Beijing; ${ }^{3}$ Department of Stomatology, \\ The First Affiliated Hospital of the Chinese PLA General Hospital, Beijing; ${ }^{4}$ The Second Dental Center, \\ Peking University School and Hospital of Stomatology, Beijing; ${ }^{5}$ Department of Oral Surgery, \\ Hospital for Oral Disease Prevention and Treatment, Harbin, Heilongjiang; ${ }^{6}$ Department of Oral and \\ Maxillofacial Surgery, Tianjin Stomatological Hospital, Tianjin, P.R. China
}

Received November 26, 2015; Accepted January 27, 2016

DOI: $10.3892 /$ or.2016.4691

\begin{abstract}
Hydrogen sulfide, the third gaseous transmitter, is one of the main causes of halitosis in the oral cavity. It is generally considered as playing a deleterious role in many oral diseases including oral cancer. However, the regulatory mechanisms involved in the effects of hydrogen sulfide on oral cancer growth remain largely unknown. In the present study, we investigated the underlying mechanisms through CCK-8 assay, EdU incorporation, real-time PCR, western blot and pathway blockade assays. Our results showed that hydrogen sulfide promoted oral cancer cell proliferation through activation of the COX2, AKT and ERK1/2 pathways in a dose-dependent manner. Blocking any of the three above pathways inhibited hydrogen sulfide-induced oral cancer cell proliferation. Meanwhile, blockade of COX2 by niflumic acid downregulated NaHS-induced p-ERK and p-AKT expression. Inactivation of the AKT pathway by GSK690693 significantly decreased NaHS-induced p-ERK1/2 expression, and inhibition of the ERK1/2 pathway by U0126 markedly increased NaHS-induced p-AKT expression. Either the AKT or ERK1/2 inhibitor did not significantly alter the COX2 expression level. Our data revealed, for the first time, that hydrogen sulfide promotes oral cancer cell proliferation through activation of the COX2/AKT/ERK1/2 axis, suggesting new potential targets to eliminate the effect of hydrogen sulfide on the development of oral cancer.
\end{abstract}

Correspondence to: Dr Yixiang Wang, Central Laboratory, Peking University School and Hospital of Stomatology, 22 Zhongguancun Avenue South, Haidian, Beijing 100081, P.R. China

E-mail:kqwangyx@bjmu.edu.cn

Key words: hydrogen sulfide, oral cancer, proliferation, mechanism, COX2/AKT/ERK axis

\section{Introduction}

Oral cancer is the eighth most common cancer worldwide as reported by the International Agency for Research on Cancer of the World Health Organization (1). The 5-year survival rate of oral cancer patients has remained at $50 \%$ for the past decades (2). Information regarding the development of oral cancer remains largely unknown.

The oral cavity is a viable environment for millions of bacteria. Some of them, such as Genera fusobacterium, Treponema denticola, Porphyromonas endodontics and Porphyromonas gingivalis, are oral resident endogenetic bacteria, which have a capacity to produce hydrogen sulfide $\left(\mathrm{H}_{2} \mathrm{~S}\right)(3) . \mathrm{H}_{2} \mathrm{~S}$ was previously known as a toxic gas. To date, $\mathrm{H}_{2} \mathrm{~S}$ is considered as the third gaseotransmitter along with nitric oxide and carbon monoxide, and exerts important physiological and pathological functions in the entire body. For example, $\mathrm{H}_{2} \mathrm{~S}$ is involved in the process of oxidative stress-induced cytotoxicity (4-6), cardioprotection (7-9), inflammation (10-12) and cancer development $(13,14)$. However, the underlying mechanisms regulating the multiple functions of $\mathrm{H}_{2} \mathrm{~S}$ in many tissues and organs remain unknown.

Considering that $\mathrm{H}_{2} \mathrm{~S}$ is one of the main causes of halitosis (3) and represents an index of oral hygiene (15) and gastrointestinal health (16), $\mathrm{H}_{2} \mathrm{~S}$ is thought to be associated with oral diseases including periodontitis $(17)$ and oral cancer $(18,19)$. Previous studies have shown that $\mathrm{H}_{2} \mathrm{~S}$ can enhance the severity of periodontitis $(17,20)$. In addition, an $\mathrm{H}_{2} \mathrm{~S}$ controlled-releasing drug has been developed for the treatment of cardiovascular disease (21). If oral cancer patients use a controlled release $\mathrm{H}_{2} \mathrm{~S}$ drug to manage their cardiovascular disease, it is important to elucidate the effects of $\mathrm{H}_{2} \mathrm{~S}$ on oral cancer. The effects of $\mathrm{H}_{2} \mathrm{~S}$ on oral cancer remain largely unknown.

In this study, we investigated the effect of $\mathrm{H}_{2} \mathrm{~S}$ on oral cancer cell proliferation and the mechanisms involved using three oral squamous cell carcinoma cell lines, WSU-HN6 CAL27 and Tca83, through CCK-8, EdU incorporation, flow cytometry, pathway inhibition, real-time PCR and western blot assays. 


\section{Materials and methods}

Reagents. Sodium hydrosulfide (NaHS) was obtained from Sigma-Aldrich (St. Louis, MO, USA). Freshly made NaHS solution was used as a hydrogen sulfide donor. Antibodies against cyclooxygenase 2 (COX2), phosphorylated ERK1/2 (p-ERK), total ERK1/2 (t-ERK), phosphorylated AKT (p-AKT), and total AKT (t-AKT), were purchased from Cell Signaling Technology (Danvers, MA, USA). An antibody against GAPDH was purchased from Santa Cruz Biotechnology (Santa Cruz, CA, USA). Dulbecco's modified Eagle's medium (DMEM), RPMI-1640 and fetal bovine serum (FBS), trypsin-EDTA solution and $1 \%$ penicillin-streptomycin solution were purchased from Invitrogen (Grand Island, NY, USA). COX2 inhibitor niflumic acid (NA), ERK pathway inhibitor U0126 and AKT pathway inhibitor GSK690693 were purchased from Sigma-Aldrich. Cell Counting Kit-8 (CCK-8) was purchased from Dojindo Laboratories (Kumamoto, Japan). Click-iT ${ }^{\circledR}$ EdU HCS Assay kit and TRIzol were purchased from Invitrogen (Carlsbad, CA, USA). GoScript ${ }^{\mathrm{TM}}$ reverse transcription system was purchased from Promega (Madison, WI, USA). SYBR Green PCR Master Mix was obtained from Roche Diagnostics (Indianapolis, IN, USA). RIPA buffer was a product of Applygen Technologies, Inc. (Beijing, China). Bicinchoninic acid (BCA) protein assay kit was purchased from Thermo Fisher Scientific Inc. (Rockford, IL, USA). Polyvinylidene difluoride membranes were purchased from Millipore Corporation (Billerica, MA, USA).

Cell culture. Human head and neck squamous cell carcinoma cell lines WSU-HN6 and CAL27 were maintained in Dulbecco's minimum essential medium (DMEM) supplemented with $10 \%$ FBS and $1 \%$ penicillin-streptomycin solution. Human head and neck squamous cell carcinoma cell line Tca83 was maintained in RPMI-1640 supplemented with $10 \%$ FBS and $1 \%$ penicillin-streptomycin solution in a humidified incubator at $37^{\circ} \mathrm{C}$ in an atmosphere of $5 \% \mathrm{CO}_{2}$.

Optimal NaHS dose finding assay. To determine the optimal dose of hydrogen sulfide for the following experiments, we used NaHS, a commonly used donor of $\mathrm{H}_{2} \mathrm{~S}$, to treat the oral cancer cells for $5 \mathrm{~h}$ in a T25 flask with $4 \mathrm{ml}$ medium, and then detected the $\mathrm{H}_{2} \mathrm{~S}$ concentration in the atmosphere of a T25 flask by a halimeter. The optimal concentration of NaHS was based on the range of the $\mathrm{H}_{2} \mathrm{~S}$ concentration found in patients with halitosis.

CCK- 8 assay. Cell proliferation ability was evaluated using the CCK-8 assay which was performed as previously described (18). Briefly, cells were cultured in 96-well tissue culture plates $\left(1 \times 10^{4}\right.$ cells/well $)$ with $10 \%$ FBS overnight. Then, the cells were treated with $0-1,000 \mu \mathrm{M}$ NaHS (different doses of NaHS were used in different plates) and sealed with parafilm for an additional $5 \mathrm{~h}$. The cell proliferation was measured by the CCK- 8 assay according to the manufacturer's instructions.

Crystal violet assay staining assay. Cell proliferation ability was confirmed by crystal violet assay. Briefly, $1 \times 10^{5}$ cells were plated in a T25 flask with $5 \mathrm{ml}$ complete medium overnight. On the following day, the cells were treated with various doses of NaHS for 3 days. The cells were fixed with 95\% alcohol, stained with crystal violet, and photographed using a digital camera. Then crystal violet was discolored from the stained cells using 33\% glacial acetic acid. The optical density $(\mathrm{OD})_{570}$ of the crystal violet correlates with the number of stained cells.

EdU incorporation assay. Cell proliferation ability was also detected using the 5-ethynyl-2-deoxyuridine (EdU) incorporation assay. Briefly, $5 \times 10^{5}$ cells were plated in a T25 flask with $5 \mathrm{ml}$ complete medium overnight, and then the cells were serum-starved. At $24 \mathrm{~h}$ post-starvation, the cells were treated with various doses of NaHS in the presence of EdU for an additional $5 \mathrm{~h}$. The labeled cells were trypsinized for EdU incorporation assay using the Click-iT EdU HCS assay kit (Invitrogen). EdU-positive cells were detected by flow cytometry.

Real-time PCR. Cells in mid-logarithmic growth were used for real-time PCR. Total RNA was extracted from the tumor cells using TRIzol reagent, and cDNA was obtained by reverse transcription with the GoScript ${ }^{\mathrm{TM}}$ reverse transcription system. Relative quantitative real-time PCR reactions were performed with SYBR Green PCR Master Mix in an ABI Prism 7500 sequence detection system (Applied Biosystems Life Technologies, Foster City, CA, USA). Glyceraldehyde-3phosphate dehydrogenase (GAPDH) was used as the endogenous control. The sequences of the COX2 primers were 5'-CTGGCGCTCAGCCATACAG-3' and 5'-ACACTCATACA TACACCTCGGT-3'. The thermal cycling consisted of $10 \mathrm{~min}$ at $95^{\circ} \mathrm{C}$, followed by 40 cycles at $95^{\circ} \mathrm{C}$ for $15 \mathrm{sec}$, and at $60^{\circ} \mathrm{C}$ for $1 \mathrm{~min}$. All amplifications were performed in triplicate for each sample and repeated three times independently. Relative expression of the target genes was analyzed using the $2^{-\Delta \Delta C t}$ method.

Western blot analysis. Cells were lysed on ice in RIPA buffer supplemented with protease inhibitors (Roche Diagnostics). The concentration of total protein was determined using the BCA protein assay kit. Equal quantities of protein $(30 \mu \mathrm{g})$ were separated by sodium dodecyl sulfate-polyacrylamide gel electrophoresis and transferred to polyvinylidene difluoride membranes. The membranes were blocked in 5\% nonfat dry milk for $1 \mathrm{~h}$ and probed with primary antibodies against GAPDH, COX2, p-ERK, t-ERK, p-AKT, t-AKT, respectively, at $4^{\circ} \mathrm{C}$ overnight. After incubation with horseradish peroxidase (HRP)-linked secondary antibodies, the protein bands were visualized using an enhanced chemiluminescent substrate (Applygen Technologies).

Pathway inhibition assay. To investigate the role of COX2, ERK and AKT pathways in hydrogen sulfide-induced cancer cell proliferation, pathway inhibition assays were carried out using an inhibitor for each molecule/pathway. Based on our preliminary data and previous studies (22-24), we found that COX 2 could be markedly downregulated by $100 \mu \mathrm{M}$ niflumic acid (NA) at $24 \mathrm{~h}$ post-treatment; p-ERK and p-AKT could be significantly blocked by $50 \mu \mathrm{M}$ U0126 and $1 \mu \mathrm{M}$ GSK690693 at $1 \mathrm{~h}$ post-treatment, respectively. Therefore, in the present 
A

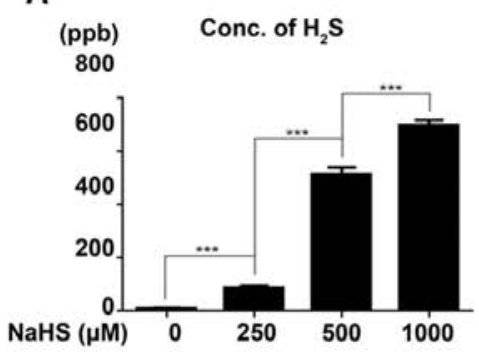

B
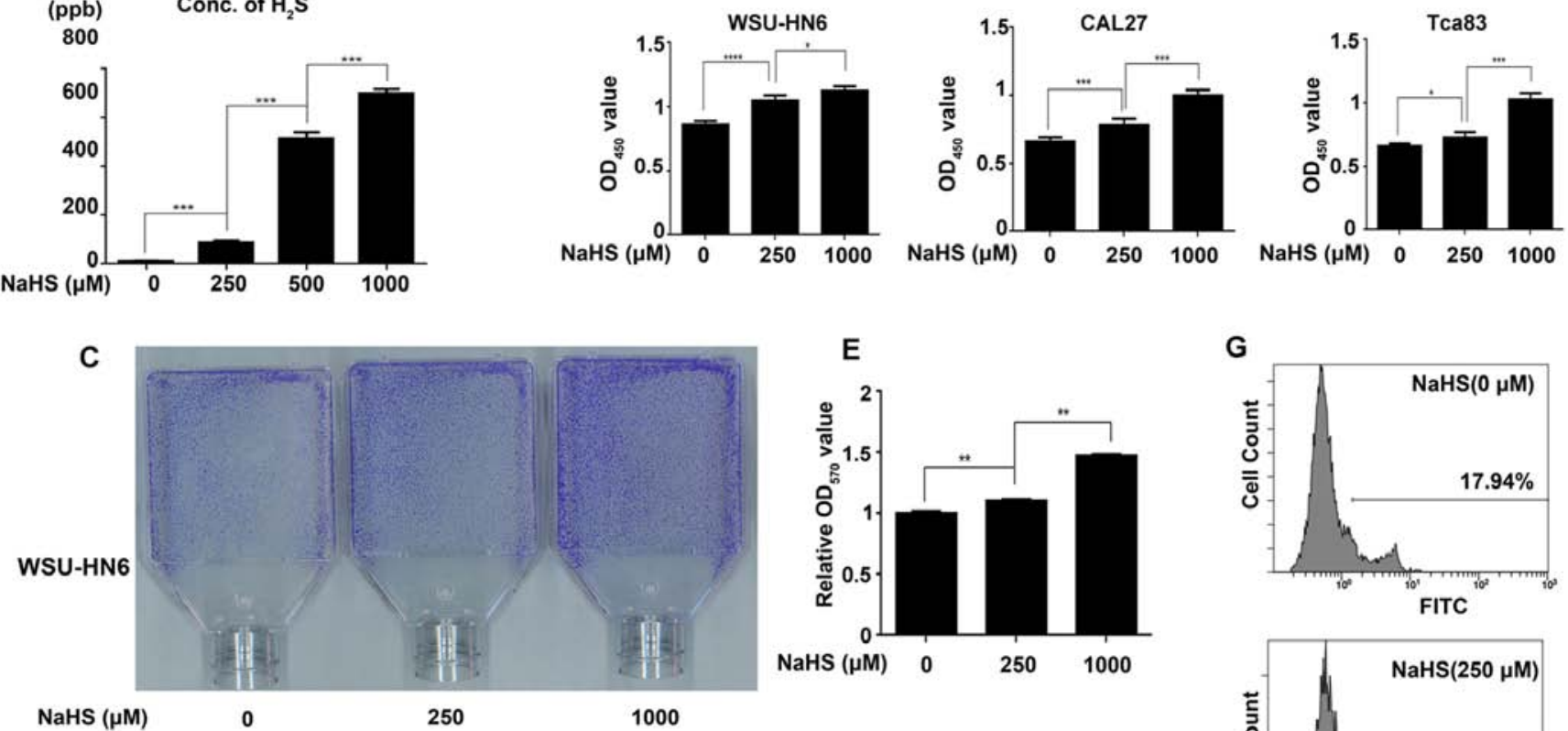

G
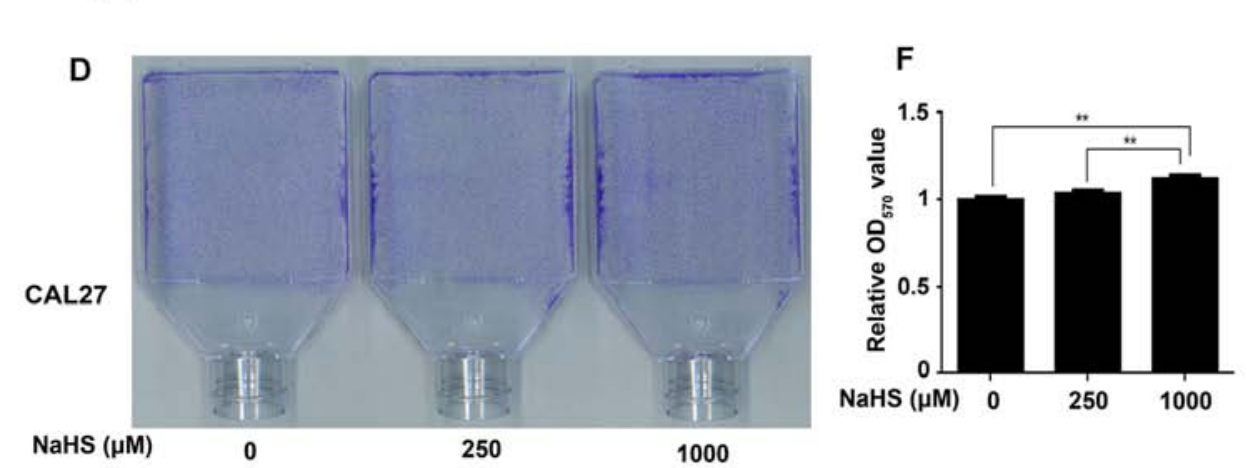
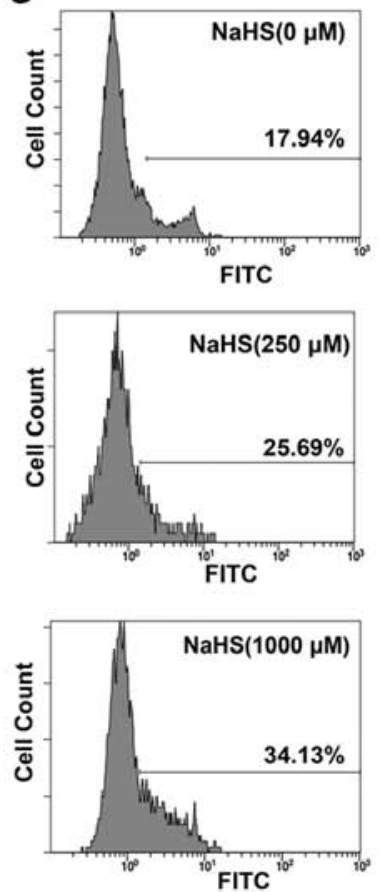

Figure 1. $\mathrm{H}_{2} \mathrm{~S}$ promotes oral cancer cell proliferation. (A) Measurement of the $\mathrm{H}_{2} \mathrm{~S}$ concentration released from various doses of NaHS in the atmosphere of the T25 flask with 4-ml culture medium determined using a halimeter. (B) CCK-8 assays were used to determine the proliferative effect of a 5-h NaHS treatment at the indicated concentrations in the WSU-HN6, CAL27 and Tca83 cells. (C and D) Representative images of WSU-HN6 and CAL27 cells treated with the indicated doses of NaHS for 3 days, following fixation with $95 \%$ alcohol and staining with crystal violet. (E and F) The optical density (OD) 570 of the crystal violet released from the stained WSU-HN6 and CAL27 cells. $(\mathrm{G})$ EdU incorporation assay was used to confirm the CCK-8 assay and crystal violet staining assay results in the WSU-HN6 cell line. ${ }^{*} \mathrm{P}<0.05,{ }^{* *} \mathrm{P}<0.01$ and ${ }^{* * * *} \mathrm{P}<0.001$.

study, WSU-HN6 cells were pretreated with either COX2 inhibitor NA for $24 \mathrm{~h}$, ERK pathway inhibitor U0126 for $1 \mathrm{~h}$, or AKT pathway inhibitor GSK690693 for $1 \mathrm{~h}$, under serumstarvation condition, and then exposed to NaHS for $5 \mathrm{~h}$ for the real-time PCR and western blot assays or with EdU reagent for the EdU incorporation assay.

Statistical analysis. The results are expressed as mean \pm SD. Differences between groups were analyzed by one-way ANOVA. Significance was established at the $\mathrm{P}<0.05$ level.

\section{Results}

Determination of the optimal NaHS concentration. The NaHS dose finding assay showed that the concentration of $\mathrm{H}_{2} \mathrm{~S}$ in the atmosphere of $1,000 \mu \mathrm{M}$ NaHS-treated cells was $698.33 \pm 18.93 \mathrm{ppb}$, which is equal to $1073.34 \pm 29.09 \mu \mathrm{g} / 1$. Based on previous studies, the concentration of $\mathrm{H}_{2} \mathrm{~S}$ in patients with halitosis is $810.30 \pm 204.09 \mu \mathrm{g} / 1$ (25). Therefore, the $\mathrm{H}_{2} \mathrm{~S}$ concentration released from 250,500 and $1,000 \mu \mathrm{M}$ NaHS was comparable with the $\mathrm{H}_{2} \mathrm{~S}$ concentration found in the oral cavity of patients with halitosis, and 1,000 $\mu \mathrm{M}$ NaHS was in the range of the highest concentration of $\mathrm{H}_{2} \mathrm{~S}$ in the oral cavity of halitosis patients (Fig. 1A).

$\mathrm{H}_{2} \mathrm{~S}$ promotes the growth of oral cancer cells. To evaluate the effect of $\mathrm{H}_{2} \mathrm{~S}$ on oral cancer cell proliferation, the CCK-8, crystal violet staining and EdU incorporation assays were performed. The CCK- 8 assay showed that $\mathrm{H}_{2} \mathrm{~S}$ significantly promoted the proliferation of the WSU-HN6 and CAL27 cells in a dose-dependent manner. The WSU-HN6, CAL27 and Tca83 cells treated with 1,000 $\mu \mathrm{M}$ NaHS exhibited a $22.94,33.79$ and $32.20 \%$ increase in proliferation, respectively (Fig. 1B, $\mathrm{P}<0.05)$. Crystal violet staining assay showed that the cell growth of WSU-HN6 and CAL27 cells was accelerated by NaHS in a dose-dependent manner (Fig. 1C-F). The CCK-8 results were further confirmed in the WSU-HN6 cells using the EdU incorporation assay, which showed a 16.19 $\pm 1.89 \%$ increase in the proliferation of the WSU-HN6 cells following treatment with 1,000 $\mu \mathrm{M}$ NaHS (Fig. 1G, P<0.05). 
A

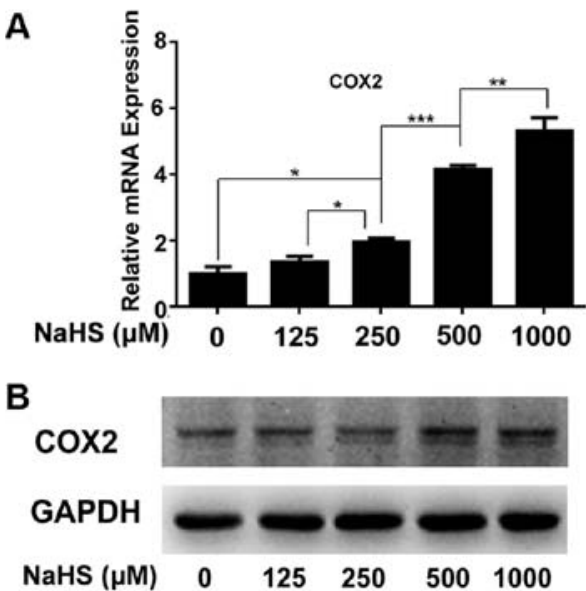

C

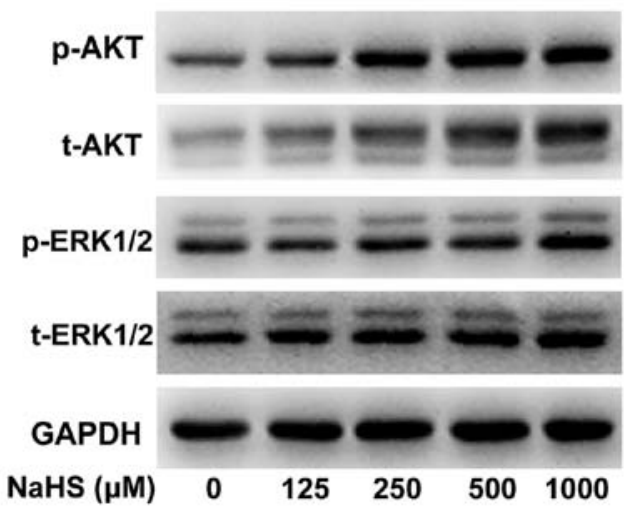

Figure 2. $\mathrm{H}_{2} \mathrm{~S}$ activates the COX2, AKT and ERK1/2 pathways. After a 5-h treatment with NaHS $(0-1,000 \mu \mathrm{M})$, WSU-HN6 cells were harvested for real-time PCR and western blotting. (A) Real-time PCR showed that NaHS dose-dependently increased the expression of COX2 at the mRNA level. (B and C) Western blotting showed that NaHS dose-dependently increased the expression of COX2 and upregulated the expression of p-AKT and p-ERK1/2 at the protein level. ${ }^{*} \mathrm{P}<0.05,{ }^{* *} \mathrm{P}<0.01$ and ${ }^{* * * *} \mathrm{P}<0.001$

A
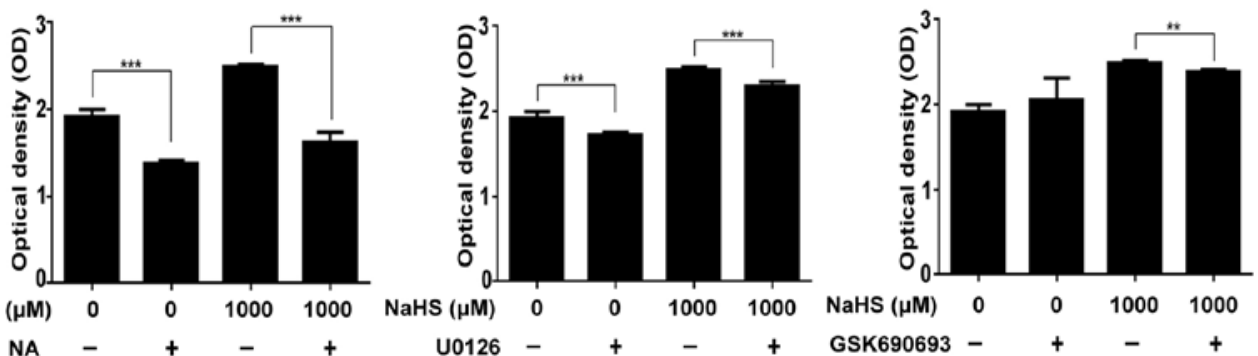

B
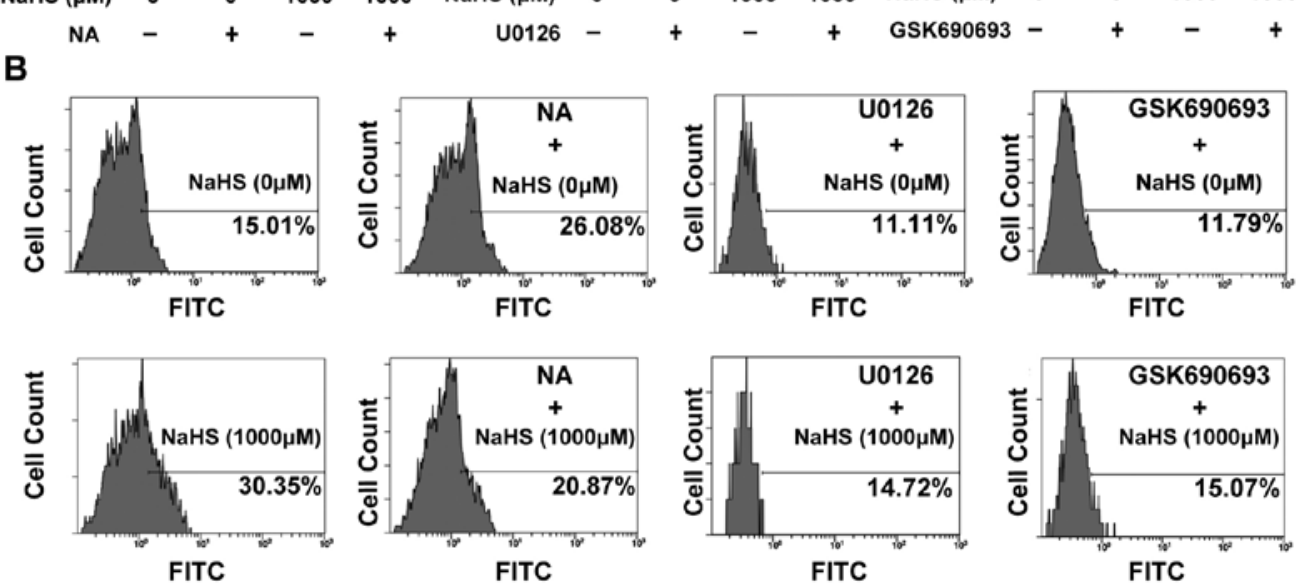

Figure 3. NA (niflumic acid, COX2 inhibitor), U0126 (ERK1/2 pathway inhibitor) and GSK690593 (AKT pathway inhibitor) inhibit $\mathrm{H}_{2} \mathrm{~S}$-induced oral cancer cell proliferation in the WSU-HN6 cell line, respectively. (A) CCK-8 proliferation assay showed that NA, U0126 and GSK690693 can respectively decrease the effect of the $\mathrm{H}_{2} \mathrm{~S}$-induced oral cancer cell proliferation. (B) EdU incorporation data are consistent with the CCK-8 results. ${ }^{* * *} \mathrm{P}<0.01 ;{ }^{* * * *} \mathrm{P}<0.001$.

$\mathrm{H}_{2} \mathrm{~S}$ promotes oral cancer cell proliferation through the activation of COX2, ERK and AKT signaling pathways. To analyze the molecular changes during NaHS-induced cancer cell proliferation, we detected the changes in cancer proliferation-related molecule COX2 by real-time PCR (Fig. 2A) and western blotting (Fig. 2B), and pathways including ERK and AKT by western blotting (Fig. 2C). The results showed that compared with the corresponding controls, hydrogen sulfide markedly upregulated COX2 at the mRNA and protein levels in a dose-dependent manner (Fig. 2A and B). Meanwhile, $\mathrm{H}_{2} \mathrm{~S}$ significantly activated p-ERK and p-AKT expression in a dose-dependent manner (Fig. 2C).

Inhibition of $C O X 2, E R K$ and AKT by their corresponding inhibitors significantly blocks $\mathrm{H}_{2} \mathrm{~S}$-induced oral cancer cell proliferation. To investigate the role of $\mathrm{COX} 2$, the ERK and AKT pathways in $\mathrm{H}_{2} \mathrm{~S}$-induced oral cancer cell proliferation, we uses the CCK-8 and EdU cellular incorporation assays to detect the change in proliferation. The proliferation of WSU-HN6 cells caused by $\mathrm{H}_{2} \mathrm{~S}$ was decreased by inhibition 

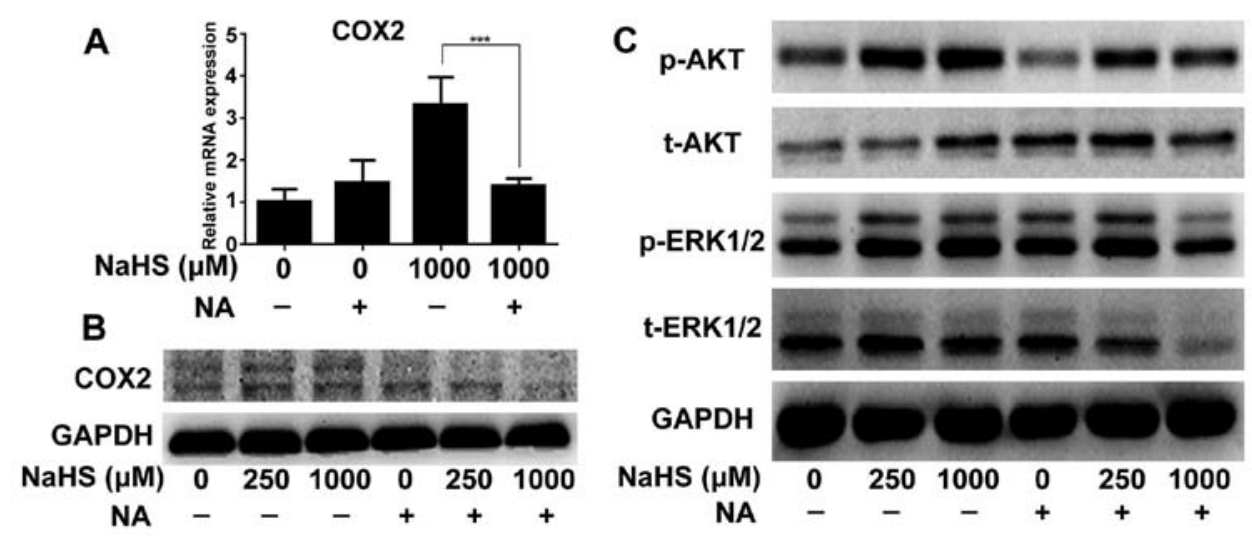

Figure 4. Effect of COX2 inhibitor NA on the NaHS-induced expression pattern of COX2, AKT and ERK1/2 in WSU-HN6 cells. WSU-HN6 cells were subjected to pretreatment with NA for $24 \mathrm{~h}$, and then treated with 0-1,000 $\mu \mathrm{M} \mathrm{NaHS}$ for $5 \mathrm{~h}$. (A) Real-time PCR showed that NA abolished $\mathrm{H}_{2} \mathrm{~S}$-induced increase of COX2 at the mRNA level. (B and C) Western blotting shows that NA downregulated the elevated expression pattern of COX2, p-AKT and p-ERK1/2. **** $\mathrm{P}<0.001$.
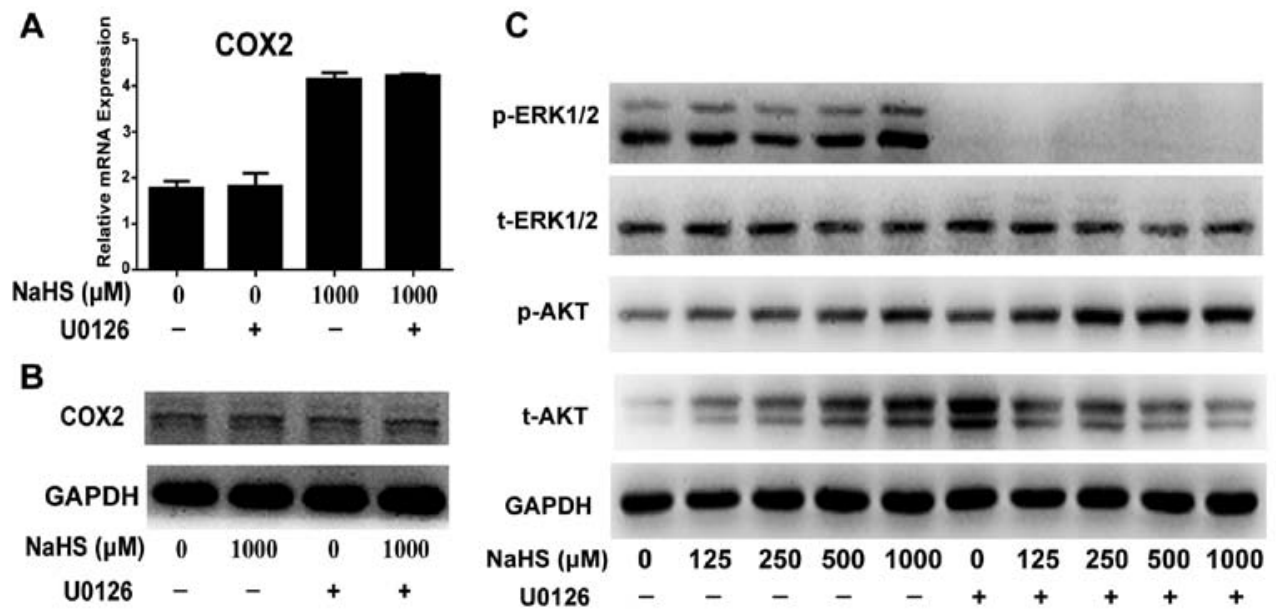

Figure 5. Effects of ERK1/2 inhibitor U0126 on the changes in NaHS-induced COX2, p-AKT and p-ERK1/2 expression pattern. WSU-HN6 cells were subjected to pretreatment with U0126 for $1 \mathrm{~h}$, and then treated with NaHS for $5 \mathrm{~h}$. Real-time PCR (A) and western blotting (B) showed that pretreatment of U0126 did not alter the COX2 expression pattern induced by NaHS at the mRNA and protein levels. (C) Western blotting showed that pretreatment with U0126 completely blocked p-ERK1/2 expression, and also upregulated p-AKT expression along with an increase in NaHS concentrations.

of COX2, ERK and AKT pathways. CCK-8 assay showed that in the WSU-HN6 cells, treatment of NA (COX2 inhibitor) resulted in a nearly $50 \%$ decrease in growth caused by $\mathrm{H}_{2} \mathrm{~S}$. Meanwhile, U0126 (ERK pathway inhibitor) and GSK690693 (AKT pathway inhibitor) achieved a less significant decrease in proliferation as determined by the CCK-8 assay (Fig. 3A).

The EdU incorporation assay further confirmed the CCK-8 results. Compared with the untreated control, all these inhibitors alone decreased the percentage of EdU-positive cells while NaHS alone increased the percentage of EdU-positive cells. NA alone caused a $11.07 \pm 3.71 \%$ increase, while U0126 and GSK690693 caused a $3.9 \pm 0.98$ and $3.22 \pm 1.00 \%$ decrease in the WSU-HN6 cells. Compared with NaHS treatment alone, NaHS in combination with NA yielded a $31.24 \pm 6.39 \%$

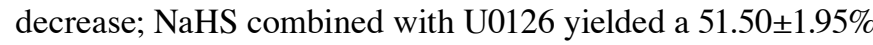
decrease; and NaHS plus GSK690693 yielded a 50.35 $\pm 1.89 \%$ decrease in Edu-positive cells. The results above indicated that $\mathrm{H}_{2} \mathrm{~S}$-induced upregulation of COX2, p-ERK and p-AKT plays a positive role in the process of $\mathrm{H}_{2} \mathrm{~S}$-induced proliferation of oral cancer cells (Fig. 3B).
COX2 inhibitor downregulates NaHS-induced $p$-AKT and $p$-ERK expression. To further verify the role of COX2 in the promotion of proliferation, we detected the changes in the ERK and AKT pathway folowing the treatment of NA. NA not only decreased COX2 expression caused by $\mathrm{H}_{2} \mathrm{~S}$ at the mRNA and protein levels (Fig. 4A and B), but also decreased p-ERK and p-AKT expression when the cells were treated with 1,000 $\mu \mathrm{M}$ of NaHS (Fig. 4C).

Blockade of the ERK pathway by U0126 upregulates $\mathrm{H}_{2} \mathrm{~S}$-induced p-AKT expression, but does not affect $\mathrm{H}_{2} \mathrm{~S}$ induced COX2 expression. To investigate the role of the ERK pathway in proliferation, U0126 was used to inhibit p-ERK. Western blotting showed that U0126 completely blocked the activation of the ERK pathway by eliminating p-ERK expression (Fig. 5C). Real-time PCR and western blotting showed that inhibition of the ERK pathway by U0126 did not change COX2 expression at the mRNA and protein levels (Fig. 5A and B). Furthermore, U0126 increased the activation of the $\mathrm{H}_{2} \mathrm{~S}$-induced p-AKT pathway (Fig. 5C). 

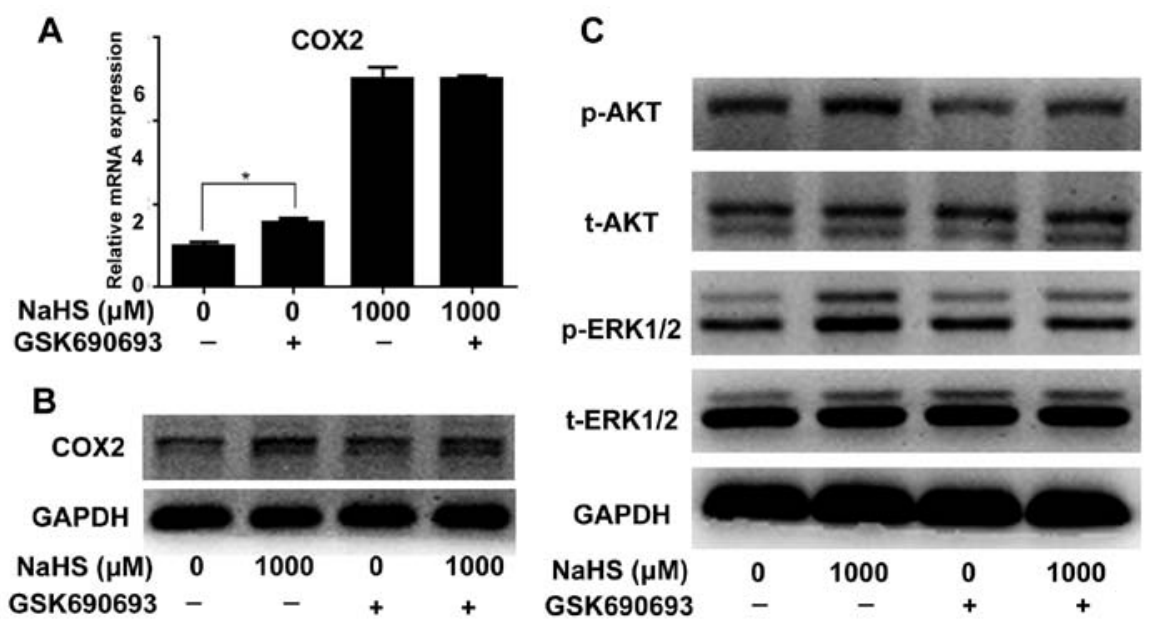

Figure 6. Effects of AKT inhibitor GSK690693 on the changes in NaHS-induced COX2, p-AKT and p-ERK1/2 expression pattern. WSU-HN6 cells were subjected to pretreatment with GSK690693 for $1 \mathrm{~h}$, and then treated with NaHS for $5 \mathrm{~h}$. Real-time PCR (A) and western blotting (B) showed that pretreatment of U0126 did not alter the COX2 expression pattern induced by NaHS at the mRNA and protein levels. (C) Western blotting showed that pretreatment of GSK690693 reduced the p-AKT expression induced by $1,000 \mu \mathrm{M}$ NaHS, and also markedly inhibited p-ERK1/2 expression mediated by $1,000 \mu \mathrm{M}$. $\mathrm{P}<0.05$.

Blockade of the AKT pathway downregulates $\mathrm{H}_{2} \mathrm{~S}$-induced p-ERK expression, but does not affect $\mathrm{H}_{2} \mathrm{~S}$-induced COX2 expression. To verify the role of the AKT pathway in $\mathrm{H}_{2} \mathrm{~S}$-induced cell proliferation, GSK690693 was used for inhibition of p-AKT. Western blotting showed that GSK690693 decreased the expression of p-AKT (Fig. 6C). Real-time PCR results showed that GSK690693 did not change $\mathrm{H}_{2} \mathrm{~S}$-induced COX2 expression at the mRNA and protein levels (Fig. 6A and B), although GSK690693 alone induced an increase in COX2 at the mRNA level. In addition, inhibition of the AKT pathway decreased the expression level of p-ERK (Fig. 6C).

\section{Discussion}

$\mathrm{H}_{2} \mathrm{~S}$ is characterized by its rotten egg odor yet exists widespread in the body. It is produced naturally by either protein metabolism through cystathionine $\gamma$-lyase, (CSE), cystathionine- $\beta$-synthase (CBS), and 3-Mercaptopyruvate sulfurtransferase (3-MT), or bacteria existing in the digestive, respiratory or genital tracts reducing compound-containing sulfur element (26). Since it has been identified as the third gaseotransmitter playing an important physiological and pathological role in the body, more attention has been given to its beneficial properties in many organs and systems. However, in the oral cavity, $\mathrm{H}_{2} \mathrm{~S}$ is commonly considered to play a deleterious role. For example, $\mathrm{H}_{2} \mathrm{~S}$ is taken as one of the main contributors of bad mouth breath (halitosis), which is often associated with dental plaque and periodontal disease $(17,20)$. Moreover, $\mathrm{H}_{2} \mathrm{~S}$ can promote cell cycle progression in oral cancer cells (18). However, the mechanisms involved in the regulation of oral cancer growth by $\mathrm{H}_{2} \mathrm{~S}$ are not fully elucidated.

In the present study, we investigated the underlying mechanism and found that the COX2-AKT-ERK1/2 axis is closely associated the regulation of oral cancer growth by $\mathrm{H}_{2} \mathrm{~S}$. We firstly identified that the concentrations of $\mathrm{H}_{2} \mathrm{~S}$ released from 250,500 and $1,000 \mu \mathrm{M}$ NaHS used in the T25 flask were comparable with the $\mathrm{H}_{2} \mathrm{~S}$ concentrations found in patients with halitosis. In addition, $1,000 \mu \mathrm{M}$ NaHS is in the range of the highest concentration of $\mathrm{H}_{2} \mathrm{~S}$ in the oral cavity of halitosis patients (25). Next, we confirmed that $\mathrm{H}_{2} \mathrm{~S}$ promoted oral cancer growth through CCK-8 crystal violet staining and EdU incorporation assays. Meanwhile, we found that COX2, ERK and AKT may be involved in this process through real-time PCR and western blotting.

Along with the increase in NaHS concentration, an increase in the dose-dependent proliferation of oral cancer cells and upregulation of COX2 expression were concurrent. In addition, when COX 2 expression was blocked by the COX2 inhibitor, the effect of $\mathrm{H}_{2} \mathrm{~S}$-induced oral cancer cell proliferation was completely inhibited. These results indicated that the regulation of oral cancer cell growth by $\mathrm{H}_{2} \mathrm{~S}$ was closely related with COX2 expression. It was previously found that COX2 expression has a close relationship with the proliferation of other cancers $(23,24,26-28)$. Activation of COX2 contributes to the progression from Barrett's metaplasia to esophageal cancer (27). Upregulation of COX2 expression promotes colorectal tumorigenesis and metastasis (28). Inhibition of COX2 decreases the ability of breast cancer cell motility in breast cancer tissues $(23,24)$. Of importance, a meta-analysis showed that COX2 expression in oral cancer tissues was significantly higher than that in normal benign tissues, and positive COX2 expression may be a marker of worse prognosis in oral cancer patients (29).

In addition to the COX2 molecule, we also found two important pathways (AKT and ERK pathways) associated with the $\mathrm{H}_{2} \mathrm{~S}$-induced oral cancer cell proliferation, AKT and ERK were activated during $\mathrm{H}_{2} \mathrm{~S}$-induced cell proliferation, and blockade of either ERK or AKT pathway reduced this effect. The results indicate that $\mathrm{H}_{2} \mathrm{~S}$-mediated oral cancer growth is also related with the AKT and ERK pathways. A previous study reported that ERK activation is necessary for cancer cell proliferation (30). Activation of the ERK pathway enhanced the resistance of prostate cancer and osteosarcoma cells to apoptosis (31). Scutellarein inhibits proliferation of the human lung cancer via reducing the expression levels of p-ERK 


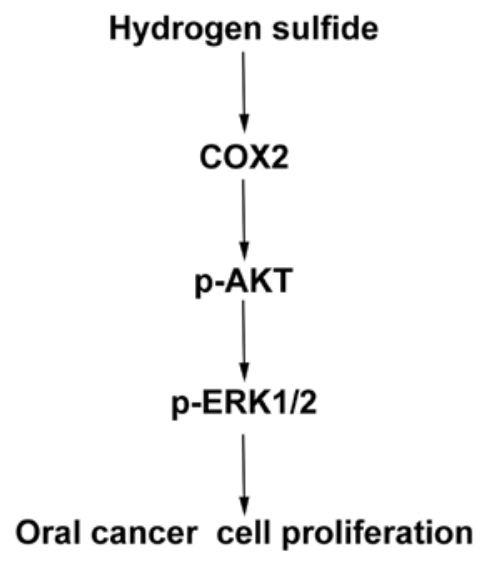

Figure 7. Proposed molecular model: $\mathrm{H}_{2} \mathrm{~S}$ induced the proliferation of oral squamous cancer carcinoma cell through COX2-AKT-ERK1/2 signaling axis. Arrows represent stimulatory modification and the activation of the indicated pathways.

(32). Baicalin dose-dependently inhibited vascular smooth muscle cell proliferation by blocking the ERK pathway (33). Activation of the AKT pathway contributes to the proliferation of gastric cancer (34) and cervical cancer cells (35). Curcumin was found to play an anticancer role by suppressing AKT phosphorylation (36). Furthermore, inactivation of the AKT and ERK pathways contributes to the inhibition of prostate cancer growth (37).

The results of this experiment are in accordance with the proliferation-promoting role of the ERK and AKT pathways. Through pathway inhibition and EdU incorporation assays, we can conclude that the COX2, ERK and AKT pathways are involved in the regulation of oral cancer growth by $\mathrm{H}_{2} \mathrm{~S}$. The next question is whether COX2, ERK and AKT pathways have a regulatory role in the hydrogen sulfide-regulated oral cancer growth. From the pathway inhibition assays, we found that blockade of COX2 clearly downregulated $\mathrm{H}_{2} \mathrm{~S}$-induced p-ERK and p-AKT expression. Inactivation of the AKT pathway markedly decreased $\mathrm{H}_{2} \mathrm{~S}$-induced $\mathrm{p}$-ERK expression but did not alter the COX2 expression level. Inhibition of the ERK pathway significantly increased $\mathrm{H}_{2} \mathrm{~S}$-induced $\mathrm{p}$-AKT expression but did not significantly alter the level of COX2 expression. Based on these data (Fig. 7), we can deduce that $\mathrm{H}_{2} \mathrm{~S}$ promotes oral cancer cell proliferation through the COX2/AKT/ERK1/2 axis. Upregulation of p-AKT expression by $\mathrm{H}_{2} \mathrm{~S}$ is due to the reactive response after blockade of the ERK pathway. The cells express more p-AKT in order to enhance the expression level of p-ERK, that is, to activate the ERK pathway.

In conclusion, in the present study, we, for the first time, identified a new mechanism elucidating that $\mathrm{H}_{2} \mathrm{~S}$ promotes oral cancer cell proliferation through the COX2/AKT/ERK1/2 axis, which may provide new potential targets by which to eliminate the effect of $\mathrm{H}_{2} \mathrm{~S}$ on oral cancer development.

\section{Acknowledgements}

The study was supported by the Research Fund for Capital Medical Development (2011-0425-02), Research Grants from the Nature Foundation of Heilongjiang Province (no. QC2014C107), National Nature Science Foundation of China (grant no. 81470707), National Natural Science Foundation of China (81300901), and Tianjin Natural Science Foundation (14JCQNJC12500).

\section{References}

1. Edwards BK, Brown ML, Wingo PA, Howe HL, Ward E, Ries LA, Schrag D, Jamison PM, Jemal A, Wu XC, et al: Annual report to the nation on the status of cancer, 1975-2002, featuring population-based trends in cancer treatment. J Natl Cancer Inst 97: 1407-1427, 2005.

2. Siegel R, Naishadham D and Jemal A: Cancer statistics, 2012. CA Cancer J Clin 62: 10-29, 2012.

3. Persson S, Edlund MB, Claesson R and Carlsson J: The formation of hydrogen sulfide and methyl mercaptan by oral bacteria. Oral Microbiol Immunol 5: 195-201, 1990.

4. Xie L, Feng H, Li S, Meng G, Liu S, Tang X, Ma Y, Han Y, Xiao Y, Gu Y, et al: SIRT3 mediates the antioxidant effect of hydrogen sulfide in endothelial cells. Antioxid Redox Signal 24: 329-343, 2016.

5. Xie ZZ, Shi MM, Xie L, Wu ZY, Li G, Hua F and Bian JS: Sulfhydration of p66Shc at cysteine59 mediates the antioxidant effect of hydrogen sulfide. Antioxid Redox Signal 21: 2531-2542, 2014.

6. Heneberg P: Reactive nitrogen species and hydrogen sulfide as regulators of protein tyrosine phosphatase activity. Antioxid Redox Signal 20: 2191-2209, 2014.

7. Calvert JW, Jha S, Gundewar S, Elrod JW, Ramachandran A, Pattillo CB, Kevil CG and Lefer DJ: Hydrogen sulfide mediates cardioprotection through Nrf2 signaling. Circ Res 105: 365-374, 2009.

8. Salloum FN, Chau VQ, Hoke NN, Abbate A, Varma A, Ockaili RA, Toldo S and Kukreja RC: Phosphodiesterase-5 inhibitor, tadalafil, protects against myocardial ischemia/ reperfusion through protein-kinase g-dependent generation of hydrogen sulfide. Circulation 120 (Suppl 11): S31-S36, 2009.

9. Kondo K, Bhushan S, King AL, Prabhu SD, Hamid T, Koenig S, Murohara T, Predmore BL, Gojon G Sr, Gojon G Jr, et al: $\mathrm{H}_{2} \mathrm{~S}$ protects against pressure overload-induced heart failure via upregulation of endothelial nitric oxide synthase. Circulation 127: 1116-1127, 2013.

10. Badiei A, Rivers-Auty J, Ang AD and Bhatia M: Inhibition of hydrogen sulfide production by gene silencing attenuates inflammatory activity of LPS-activated RAW264.7 cells. Appl Microbiol Biotechnol 97: 7845-7852, 2013.

11. Miller TW, Wang EA, Gould S, Stein EV, Kaur S, Lim L, Amarnath S, Fowler DH and Roberts DD: Hydrogen sulfide is an endogenous potentiator of T cell activation. J Biol Chem 287: 4211-4221, 2012.

12. Mok YY and Moore PK: Hydrogen sulphide is pro-inflammatory in haemorrhagic shock. Inflamm Res 57: 512-518, 2008.

13. Szabo C, Coletta C, Chao C, Módis K, Szczesny B, Papapetropoulos A and Hellmich MR: Tumor-derived hydrogen sulfide, produced by cystathionine- $\beta$-synthase, stimulates bioenergetics, cell proliferation, and angiogenesis in colon cancer. Proc Natl Acad Sci USA 110: 12474-12479, 2013.

14. Elsheikh W, Blackler RW, Flannigan KL and Wallace JL: Enhanced chemopreventive effects of a hydrogen sulfidereleasing anti-inflammatory drug (ATB-346) in experimental colorectal cancer. Nitric Oxide 41: 131-137, 2014.

15. Gokdogan O, Catli T and Ileri F: Halitosis in otorhinolaryngology practice. Iran J Otorhinolaryngol 27: 145-153, 2015.

16. Motta JP, Flannigan KL, Agbor TA, Beatty JK, Blackler RW, Workentine ML, Da Silva GJ, Wang R, Buret AG and Wallace JL: Hydrogen sulfide protects from colitis and restores intestinal microbiota biofilm and mucus production. Inflamm Bowel Dis 21: 1006-1017, 2015.

17. Zhang JH, Dong Z and Chu L: Hydrogen sulfide induces apoptosis in human periodontium cells. J Periodontal Res 45: 71-78, 2010.

18. Ma Z, Bi Q and Wang Y: Hydrogen sulfide accelerates cell cycle progression in oral squamous cell carcinoma cell lines. Oral Dis 21: 156-162, 2015.

19. Balasenthil S, Rao KS and Nagini S: Apoptosis induction by S-allylcysteine, a garlic constituent, during 7,12-dimethylbenz[a] anthracene-induced hamster buccal pouch carcinogenesis. Cell Biochem Funct 20: 263-268, 2002. 
20. Morita M and Wang HL: Association between oral malodor and adult periodontitis: A review. J Clin Periodontol 28: 813-819, 2001.

21. Wen YD and Zhu YZ: The pharmacological effects of $\mathrm{S}$-propargyl-cysteine, a novel endogenous $\mathrm{H}_{2} \mathrm{~S}$-producing compound. Handbook Exp Pharmacol 230: 325-336, 2015.

22. Kim BM, Maeng K, Lee KH and Hong SH: Combined treatment with the Cox-2 inhibitor niflumic acid and PPAR $\gamma$ ligand ciglitazone induces ER stress/caspase-8-mediated apoptosis in human lung cancer cells. Cancer Lett 300: 134-144, 2011.

23. Larkins TL, Nowell M, Singh S and Sanford GL: Inhibition of cyclooxygenase-2 decreases breast cancer cell motility, invasion and matrix metalloproteinase expression. BMC Cancer 6: 181, 2006.

24. Brueggemeier RW, Díaz-Cruz ES, Li PK, Sugimoto Y, Lin YC and Shapiro CL: Translational studies on aromatase, cyclooxygenases, and enzyme inhibitors in breast cancer. J Steroid Biochem Mol Biol 95: 129-136, 2005.

25. Wang W, Guo J, Huang D and Cheng W: Correlation of volatile sulfide compounds in the oral cavity with periodontitis and tongue coating. Zhongguo Shengwu Yixue Gongcheng Xuebao 18: 149-152, 2012 (In Chinese).

26. Moore PK, Bhatia M and Moochhala S: Hydrogen sulfide: From the smell of the past to the mediator of the future? Trends Pharmacol Sci 24: 609-611, 2003.

27. Looby E, Abdel-Latif MM, Athié-Morales V, Duggan S, Long A and Kelleher D: Deoxycholate induces COX-2 expression via Erk1/2-, p38-MAPK and AP-1-dependent mechanisms in esophageal cancer cells. BMC Cancer 9: 190, 2009.

28. Greenhough A, Smartt HJ, Moore AE, Roberts HR, Williams AC, Paraskeva $\mathrm{C}$ and Kaidi A: The COX-2/PGE2 pathway: Key roles in the hallmarks of cancer and adaptation to the tumour microenvironment. Carcinogenesis 30: 377-386, 2009.

29. Wang ZM, Liu J, Liu HB, Ye M, Zhang YF and Yang DS: Abnormal COX2 protein expression may be correlated with poor prognosis in oral cancer: A meta-analysis. Biomed Res Int 2014: 364207, 2014.
30. Chambard JC, Lefloch R, Pouysségur J and Lenormand P: ERK implication in cell cycle regulation. Biochim Biophys Acta 1773: 1299-1310, 2007.

31. Rasola A, Sciacovelli M, Chiara F, Pantic B, Brusilow WS and Bernardi P: Activation of mitochondrial ERK protects cancer cells from death through inhibition of the permeability transition. Proc Natl Acad Sci USA 107: 726-731, 2010.

32. Cheng CY, Hu CC, Yang HJ, Lee MC and Kao ES: Inhibitory effects of scutellarein on proliferation of human lung cancer A549 cells through ERK and NFKB mediated by the EGFR pathway. Chin J Physiol 57: 182-187, 2014.

33. Dong LH, Wen JK, Miao SB, Jia Z, Hu HJ, Sun RH, Wu Y and Han M: Baicalin inhibits PDGF-BB-stimulated vascular smooth muscle cell proliferation through suppressing PDGFR $\beta$-ERK signaling and increase in p27 accumulation and prevents injury-induced neointimal hyperplasia. Cell Res 20: 1252-1262, 2010.

34. Ye Y, Ge YM, Xiao MM, Guo LM, Li Q, Hao JQ, Da J, Hu WL, Zhang XD, Xu J, et al: Suppression of SHIP2 contributes to tumorigenesis and proliferation of gastric cancer cells via activation of Akt. J Gastroenterol: Jul 23, 2015 (Epub ahead of print). http://dx.doi.org/10.1007/s00535-015-1101-0.

35. Huang H, Song Y, Wu Y, Guo N, Ma Y and Qian L: Erbin loss promotes cancer cell proliferation through feedback activation of Akt-Skp2-p27 signaling. Biochem Biophys Res Commun 463: 370-376, 2015.

36. Yallapu MM, Khan S, Maher DM, Ebeling MC, Sundram V, Chauhan N, Ganju A, Balakrishna S, Gupta BK, Zafar N, et al: Anti-cancer activity of curcumin loaded nanoparticles in prostate cancer. Biomaterials 35: 8635-8648, 2014.

37. Rick FG, Schally AV, Szalontay L, Block NL, Szepeshazi K, Nadji M, Zarandi M, Hohla F, Buchholz S and Seitz S: Antagonists of growth hormone-releasing hormone inhibit growth of androgen-independent prostate cancer through inactivation of ERK and Akt kinases. Proc Natl Acad Sci USA 109: 1655-1660, 2012 